\title{
Genetic Variation and Evolution in the Red Cell Carbonic Anhydrase Isozymes of Macaque Monkeys
}

\author{
Richard E. Tashian, ${ }^{1}$ Morris Goodman, ${ }^{2}$ Verle E. Headings,${ }^{1}$ Joseph DeSimone, ${ }^{1}$ and \\ Richard H. Ward ${ }^{1}$
}

Received 7 Oct. 1970-Final 16 Nov. 1970

The electrophoretic phenotypes of the two isozymes of red cell carbonic anhydrase, $C A$ $I$ and $C A I I$, are described in nine species of macaque monkeys from southeast Asia and Japan. Twelve phenotypes of CA I, apparently under the control of seven alleles, and five phenotypes of CA II, under the control of three alleles, were found in the different macaque populations studied. Extensive electrophoretic polymorphisms of CA I were found in three species (Macaca nemestrina, Macaca speciosa, and Macaca fuscata), and polymorphisms at the CA II locus were found in Macaca irus, Macaca mulatta, and M. nemestrina. In addition to the electrophoretic polymorphisms at the CA I locus in M. nemestrina, an inherited deficiency of $C A$ I was also discovered in which approximately $30 \%$ of the individuals in all populations of M. nemestrina tested showed the deficient phenotype. Although the recessive gene controlling this deficiency appears to be an allele of the CA I locus, it is postulated that the CA I deficiency could also be under the control of a closely linked gene. The comparative data on the extent of genetic variation observed in the two isozymes of red cell carbonic anhydrase in macaques appear to support the concept that $C A$ I has evolved more rapidly than $C A$ II in mammals.

\section{INTRODUCTION}

Genetic and evolutionary variation in the two isozymes of erythrocyte carbonic anhydrase have been reported for several primate species (Barnicot et al., 1964; Tashian, 1965, 1969; Tashian et al., 1968). There is now good evidence that these two carbonic anhydrases, designated CA I or CA B and CA II or CA C (for reviews, see Edsall, 1968; Derrien and Laurent, 1969), were probably formed from a common

Supported by USPHS grant GM-15419 and NSF grants GF-253, GB-7426, and GB-15060 of the U.S.-Japan Cooperative Science and Systemic Biology Programs.

${ }^{1}$ Department of Human Genetics, University of Michigan Medical School, Ann Arbor, Michigan.

${ }^{2}$ Department of Anatomy, Wayne State University Medical School, Detroit, Michigan. 
ancestral gene by a process of complete gene duplication before the evolution of mammals ( $c f$. Nyman et al., 1968). Since this duplication, however, the CA II isozyme appears to have undergone less variation in structure and function than the other isozyme, CA I (Tashian et al., 1968).

The numerous closely related species belonging to the polytypic genus Macaca (macaque monkeys) form an ideal group of primates to study with respect to the evolution and variation of these carbonic anhydrases. The close relationship of the macaques is emphasized by the known potential for different species to produce fertile hybrids ( $c f$. Bernstein, 1966; Nesturkh, 1959; Fooden, 1964). With the exception of the Barbary "ape," Macaca sylvana, from Gibraltar, the macaque monkeys comprising the 11 other species are distributed from India across southeast Asia, including southern China, most of Indonesia, and north through the Philippines and Taiwan to Japan.

Among the features which make the carbonic anhydrases of macaques particularly useful for such evolutionary studies are (1) in several species, genetic polymorphisms are known for the electrophoretic variants of both CA I and CA II, and in one species the suppression of CA I is polymorphic; (2) the variants of CA I are especially easy to type since the specific esterase activity of the CA I of all macaques (toward $\alpha$ - or $\beta$-naphthyl acetate) is characteristically the highest known for any mammalian carbonic anhydrase; (3) CA I and CA II can be readily purified and chemically characterized; and (4) a sensitive assay is available for the quantitation of each isozyme of carbonic anhydrase in hemolysates (Tashian et al., 1968; Tashian, 1969; Headings and Tashian, 1970a,b).

The present report describes the different qualitative and quantitative phenotypes of CA I and CA II found in nine of the 11 macaque species known from southeast Asia, with designations and frequencies of the presumed alleles in the different populations examined. In addition, the evolutionary implications of some of these findings will be discussed.

\section{MATERIALS AND METHODS}

The preparation of the blood samples, as well as the electrophoretic staining methods used in this study, were performed as previously described (Tashian, 1969). Electrostarch (Electrostarch Co., Madison, Wis.) was used to make up the gels.

The CA I variants could be readily typed from the zymograms; however, because much less CA II than CA I is present in the macaque hemolysates, in addition to its lower specific esterase activity, the CA II types were determined from their protein (nigrosin staining) patterns after electrophoresis (Tashian et al., 1968).

Assuming random matings, the estimated frequencies for the deficiency gene of CA I were determined by maximum likelihood estimation using a computer program written for the IBM 1130 (Reed and Schull, 1968).

The material from Taiwan, Thailand, the Philippines, and Malaysia was obtained from reliable animal dealers in these countries by Dr. William Prychodko (Wayne State University); the samples from Pakistan were obtained by Dr. Prychodko from SEATO Medical Research Laboratory, Bangkok; the material from Celebes and the 
material designated as "miscellaneous" was obtained from Yerkes Regional Primate Center, Atlanta, Ga. (Dr. Geoffrey H. Bourne), the Oregon Regional Primate Center, Beaverton (Dr. William Montagna), and the Delta Regional Primate Center, Covington, La. (Dr. Arthur J. Riopelle), or purchased from commercial animal supply houses. The Japanese specimens were obtained through the assistance of Dr. Toshiyuki Miki (Tokyo Medical and Dental University) and Dr. Toshi Tanaka (Japan Monkey Center, Aichi).

The blood samples that were used to determine the inheritance of the CA II variants of rhesus macaques and the CA I variants of pig-tailed macaques were obtained, respectively, from breeding colonies at the University of Missouri, Columbia (Dr. James A. Gavan), and the Washington Regional Primate Center, Seattle (Dr. Lloyd A. Dillingham).

\section{RESULTS AND DISCUSSION}

\section{The Electrophoretic Phenotypes}

\section{General}

Photographs of the starch gel patterns representing all of the different types of CA I found in the various macaque species examined are shown in Figs. 1-3. Figure 4 is a composite drawing of the electrophoretic patterns of the presumed homozygotes of the seven types of CA I and the three types of CA II. The seven different electrophoretic types of CA I have been designated $a, a_{2}, b, c, d, d_{2}$, and $d_{3}$, and the three types of CA II have been designated $a, a_{2}$, and $b$. These designations are arbitrary; however, type a was generally found to be the most common type for all species examined, followed by types $b$ and $c$. The assignment of the same letter designation for the carbonic anhydrase type of different species is based only on the fact that no difference in their migration rates could be detected when they were run side by side in the same gel at $p \mathrm{H}$ 8.6. Whether or not they are structurally identical must await further analysis; such analyses are presently underway in our laboratory.

\section{The $d_{2}$ and $d_{3}$ Variants of $C A I$}

The CA I types $a, a_{2}, b, c$, and $d$ all show a similar electrophoretic pattern of their major and minor components; in other words, there is a single major component associated with a characteristic pattern of minor components. This "usual" pattern is best typified in the zymograms for CA I in the stump-tailed macaque, Macaca speciosa (Fig. 1). Since these minor components, conformational isomers (conformers), or conformational isozymes (cf. Epstein and Schechter, 1968; Derrien and Laurent, 1969; Funakoshi and Deutsch, 1968, 1969), as they have been variously designated, always show the same relative migration distances to the major, genetically determined electrophoretic type, it can be assumed that they represent secondary or acquired alterations in the CA I molecules rather than any differences in their primary structures.

In contrast to the abovementioned patterns, types $d_{2}$ and $d_{3}$ appear to be unique in that these variants, in the presumed homozygote, characteristically produce two 


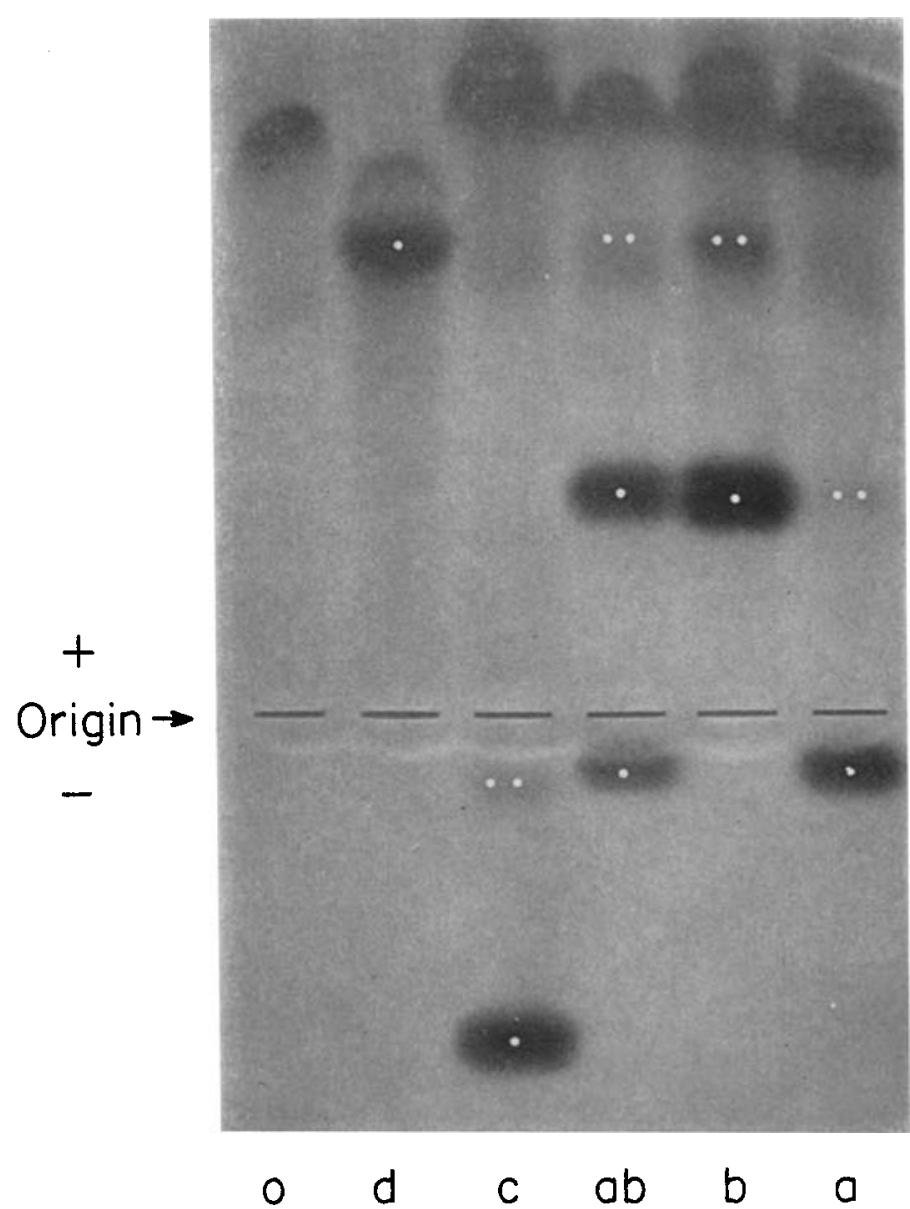

Fig. 1. The electrophoretic phenotypes and the deficiency phenotype of CA I from Macaca nemestrina (left to right): o (deficiency type), d, c, ab, $\mathrm{b}$, and a. Vertical starch gel electrophoresis was carried out at $4 \mathrm{C}$ in $0.02 \mathrm{M}$ borate- $\mathrm{NaOH}$ buffer, $p \mathrm{H} 8.6$, and $0.3 \mathrm{~m}$ borate- $\mathrm{NaOH}$ bridge buffer, $p H 8.0$ (containing $0.03 \mathrm{M} \mathrm{NaCl}$ ), for $17 \mathrm{hr}$ at $8 \mathrm{v} / \mathrm{cm}$. Single white dots indicate major CA I components, and double white dots the minor CA I components; other stained components are hemoglobins. Enzyme activity was visualized with Blue RR as dye coupler and $\beta$-naphthy] acetate as substrate.

electrophoretically distinct components in approximately equal amounts which have been designated $d_{2 a}$ and $d_{2 b}$ and $d_{3 a}$ and $d_{3 b}$ (Figs. 3 and 4). In all of the other macaque CA I types, the minor component appears to comprise only about $6-7 \%$ of the total CA I found in hemolysates (Tashian, unpublished results).

Type $\mathrm{d}_{2}$ appears to be most common in the Japanese macaque, Macaca fuscata, but it was also observed in some rhesus macaques, Macaca mulatta, and cynomolgous macaques, Macaca irus, from Thailand, and one Formosan macaque, Macaca cyclopis 


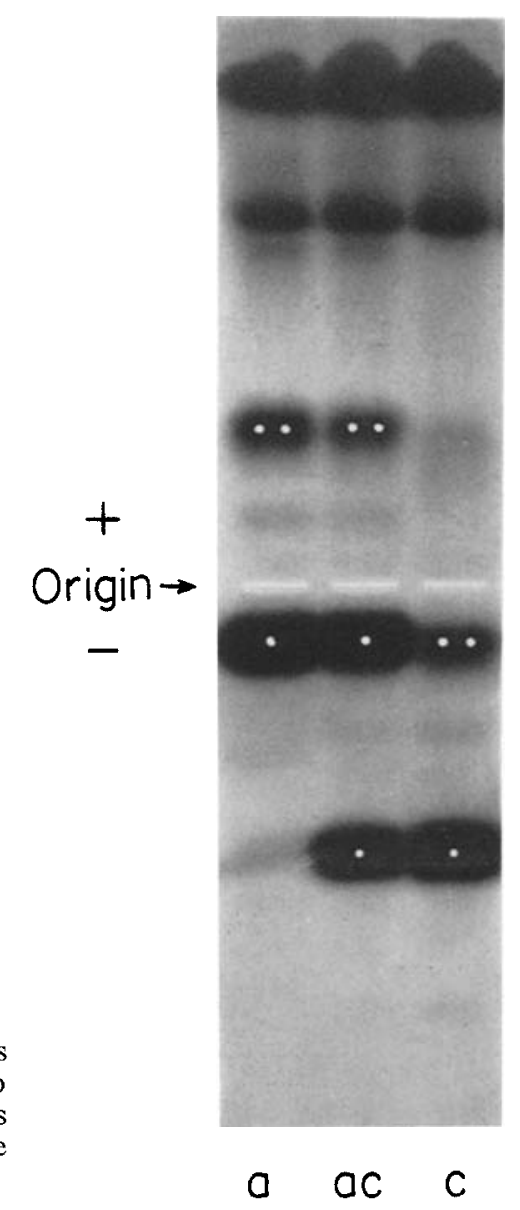

Fig. 2. The electrophoretic phenotypes of CA I from Macaca speciosa (left to right): a, ac, c. Zymogram conditions and explanation for white dots are the same as in Fig. 1.

(Tables I and II). Type $\mathrm{d}_{3}$ was seen only in the Celebes macaque, Macaca maura, and the black "ape," Macaca (= Cynopithecus) niger (Fooden, 1969), and may well be the most common type in the latter species.

As can be seen in Fig. 3 , in both the presumably heterozygous ad $a_{2}$ pattern of $M$. fuscata and the $\mathrm{a}_{2} \mathrm{~d}_{3}$ of $M$. maura, the CA I types a and $\mathrm{a}_{2}$ occur together with the characteristically "split" $\mathrm{d}_{2}$ and $\mathrm{d}_{3}$ types, respectively, giving a pattern of three bands. A pattern identical to the $\operatorname{ad}_{2}$ of $M$. fuscata was also seen in the presumably heterozygous $\operatorname{ad}_{2}$ patterns in $M$. mulatta, $M$. cyclopis, and $M$. irus.

\section{The CA I Deficiency Variant}

Of the 380 specimens of $M$. nemestrina examined, 122 showed what appeared to be a complete absence of CA I when examined by the zymogram screening method (Fig. 1). There was remarkably little variation among the different populations in the frequency $(27-33 \%)$ of this enzyme deficiency phenotype (Table I). 


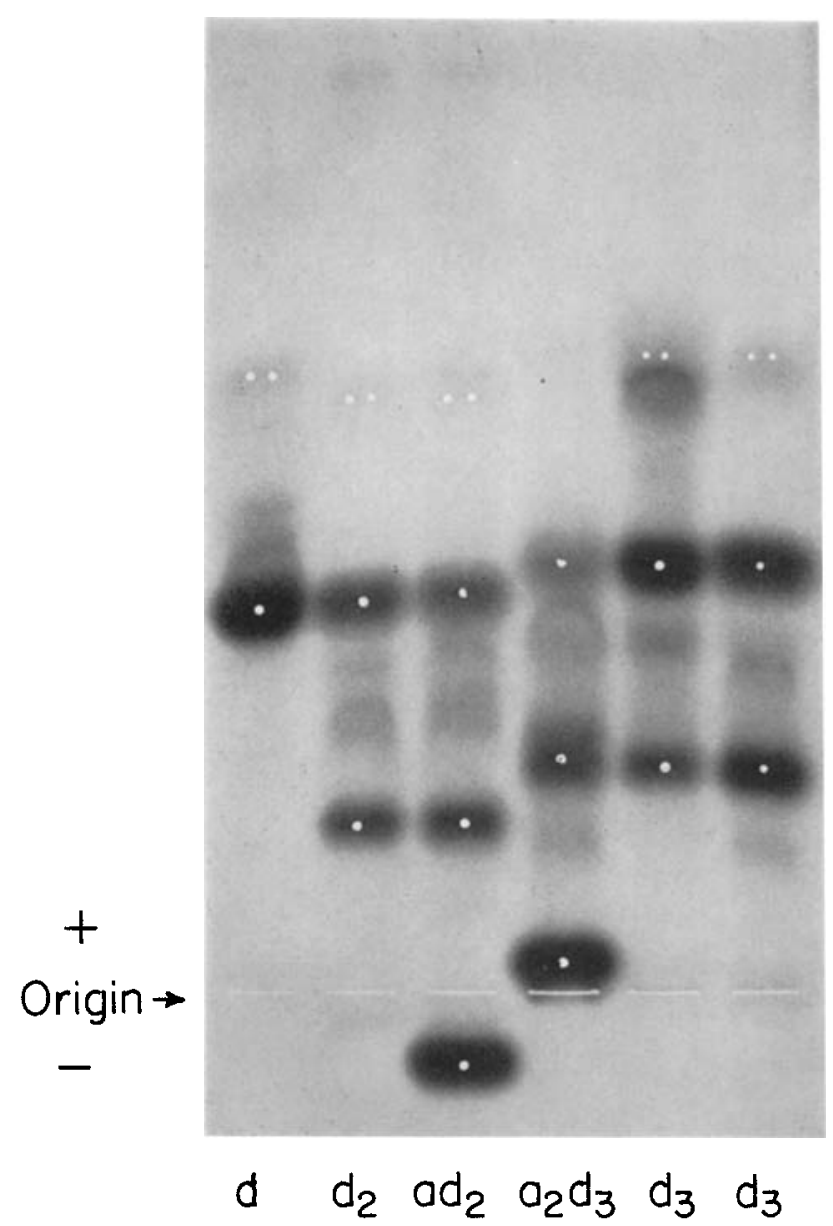

Fig. 3. Electrophoretic phenotypes of CA I from hemolysates of (left to right): $M$. nemestrina, d; $M$. fuscata, $\mathrm{d}_{2} ; M$. fuscata, $\operatorname{ad}_{2}$; $M$. maura, $\mathrm{a}_{2} \mathrm{~d}_{3} ; M$. maura, $\mathrm{d}_{3} ;$ and $M$. niger, $\mathrm{d}_{3}$. Zymogram conditions and explanation for white dots are the same as in Fig. 1. Both forms of $d_{2}$ and $d_{3}$ are designated as major components (see text).

In addition to the absence of CA I esterase activity, no protein bands could be detected (nigrosin stain) after electrophoresis in the regions where the CA I variants are known to migrate; also, no cross-reacting material could be detected in the CA I-deficient hemolysates by immunodiffusion tests with rabbit anti-human CA I sera (Headings and Tashian, 1970b). However, by means of a sensitive radioimmunoassay for CA I (Headings and Tashian, 1970a), it was possible to detect CA I levels in the deficient hemolysates which were about $0.02 \%$ of normal levels (Headings and Tashian, $1970 b)$. 


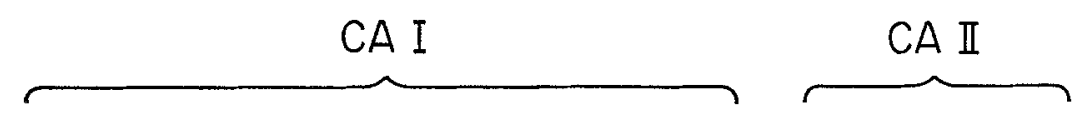

$\mathrm{d} \quad \mathrm{d}_{2 a}$

$\mathrm{b} \quad \mathrm{d}_{2 b}$

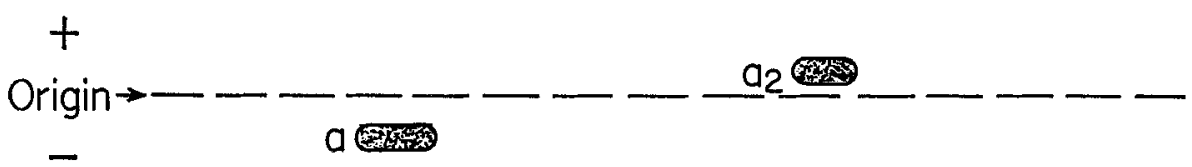

C

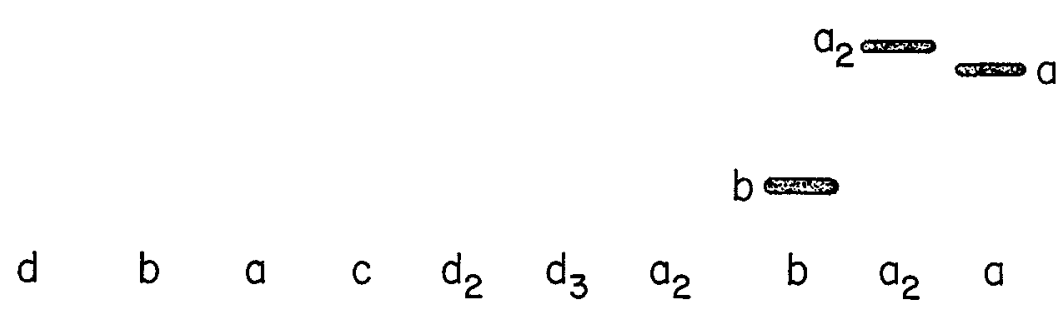

Fig. 4. Composite diagram of the major electrophoretic forms of CA I and CA II found in macaque hemolysates (left to right): CA I forms d, b, a, c, d , d , and $\mathrm{a}_{2}$; and CA II forms b, $\mathrm{a}_{2}$, and $\mathrm{a}$.

In addition, when CA I-deficient hemolysates were concentrated, it was possible to detect three electrophoretic patterns which corresponded to either the $a, b$, or $a b$ phenotypes; they were also, on immunodiffusion tests, found to be immunologically identical to CA I from normal $M$. nemestrina hemolysates (Headings and Tashian, 1970b; DeSimone, unpublished results).

A more detailed account of the quantitative aspects of CA I, as well as CA II, in the red cells and other tissues of the deficient animals is presented in another report (Headings and Tashian, 1970b).

\section{Genetic Control of the Carbonic Anhydrase Isozymes}

The CA I Variants of $\mathrm{M}$. nemestrina

The results of the crosses of six males (phenotypes $a, b, a b$, and o) with 16 different females (phenotypes $a, b, a b$, and $o$ ) in a breeding colony of pig-tailed macaques at the Washington Regional Primate Center are presented in Table III. With one excep- 


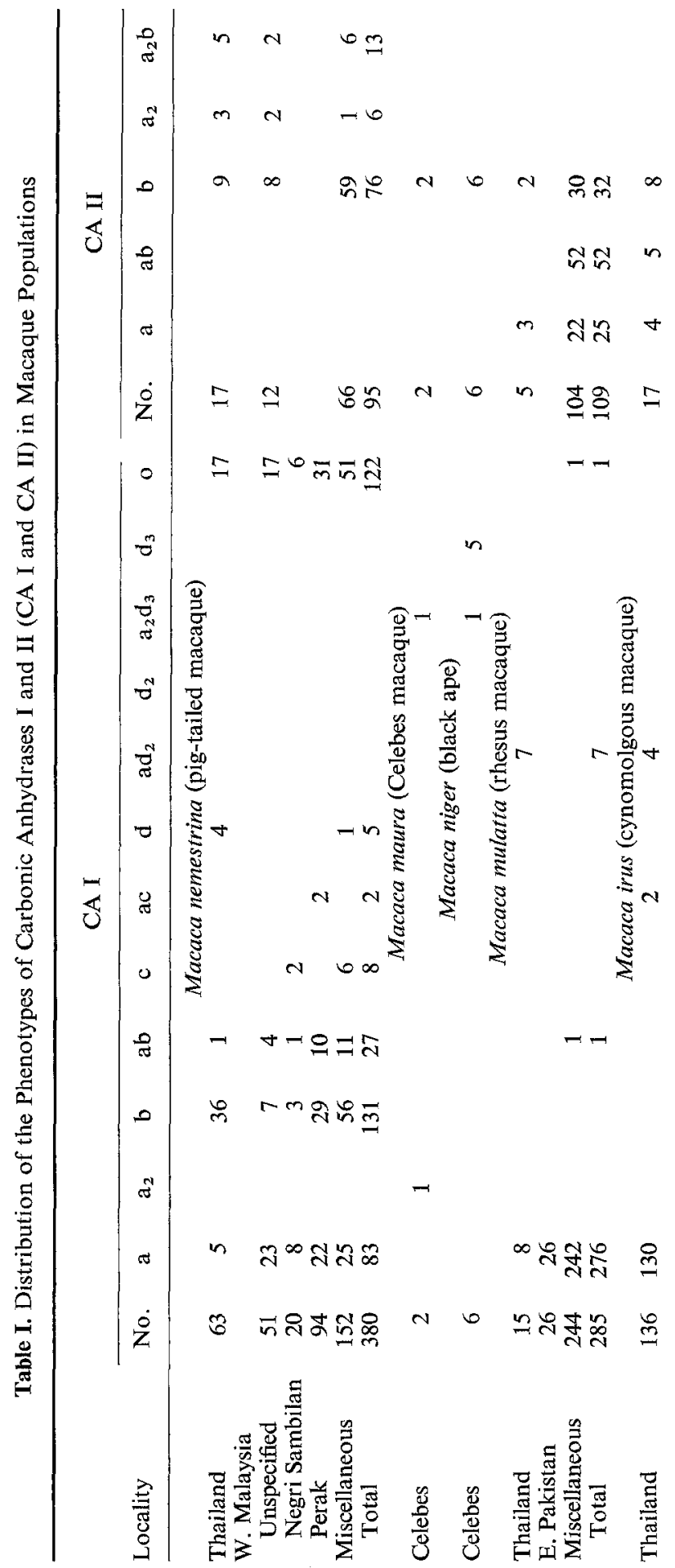




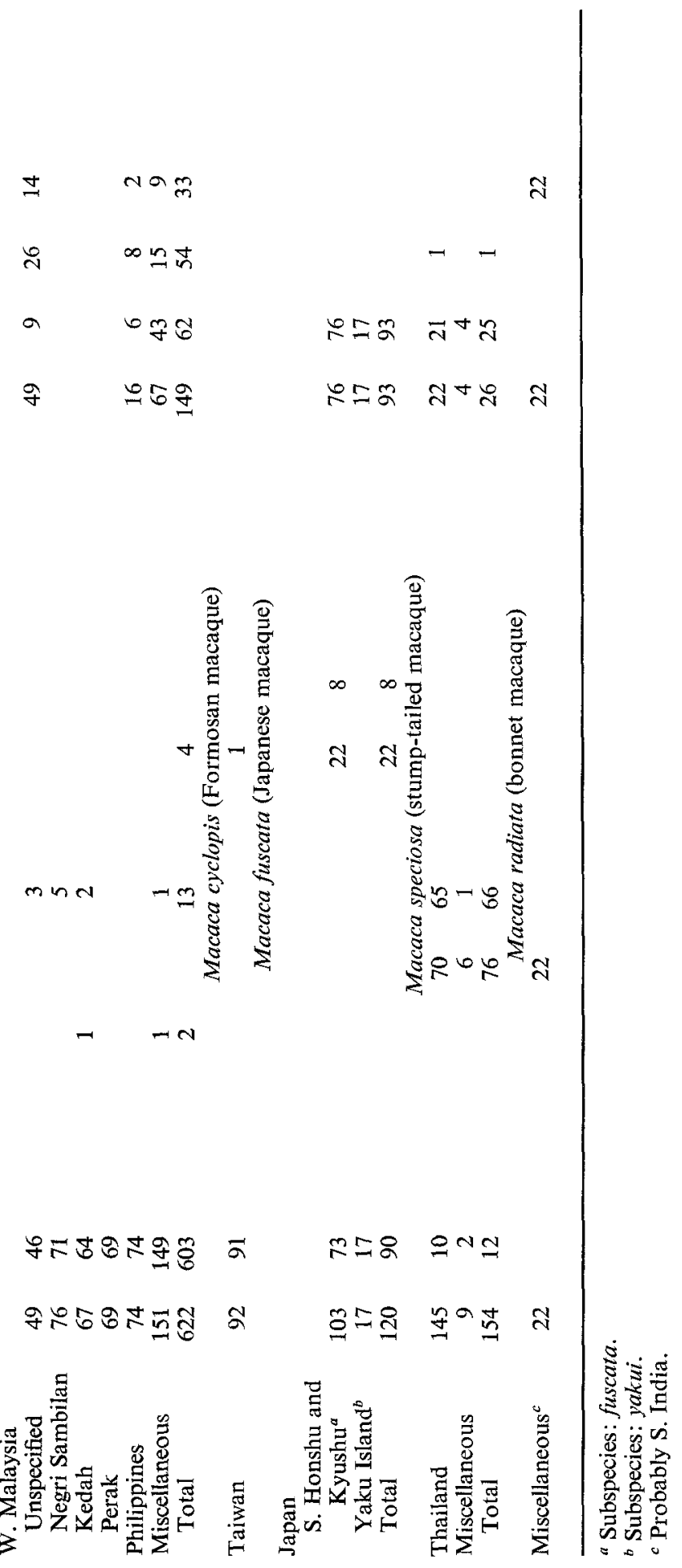




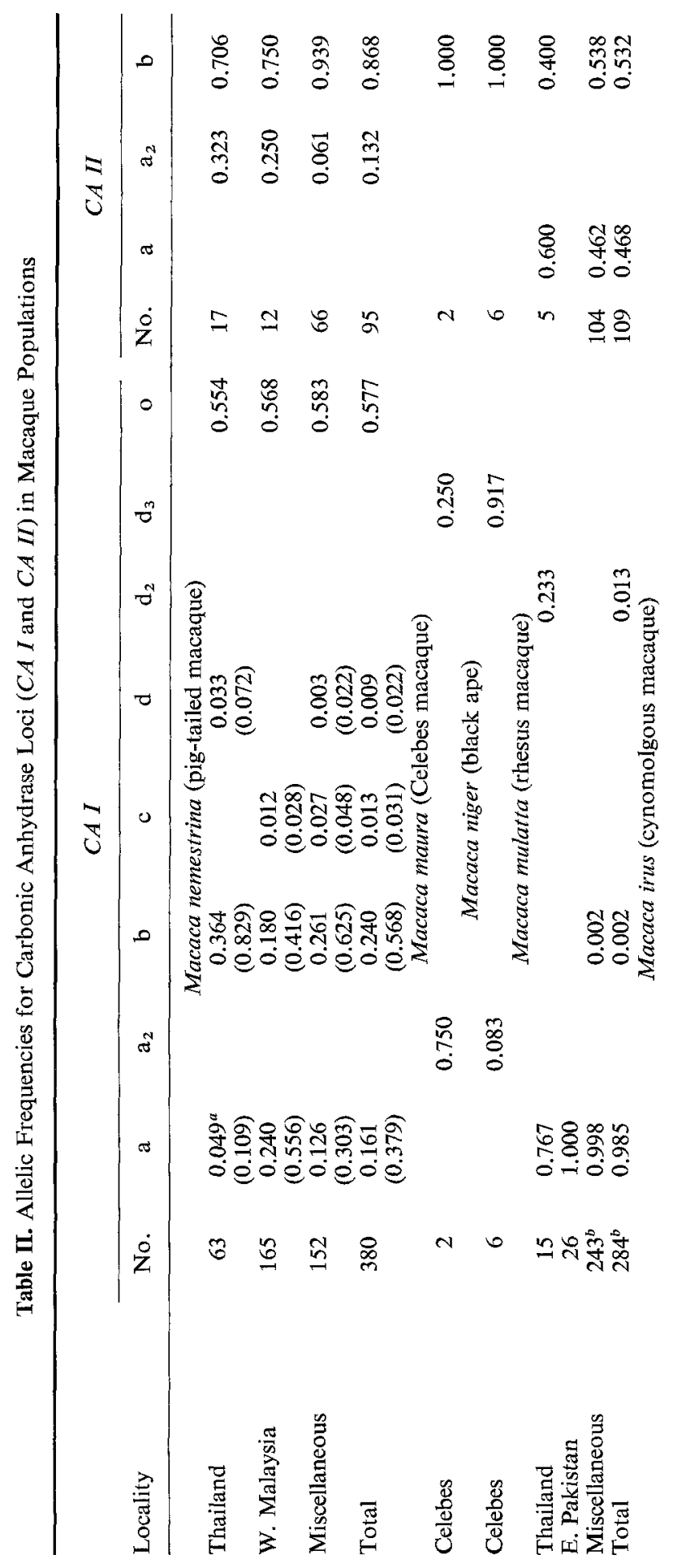




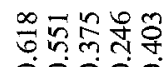

$$
\text { 잉 }
$$

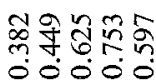

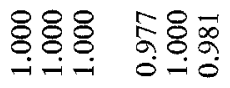

궁ำ

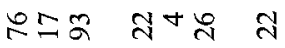

$\stackrel{n}{\circ}$

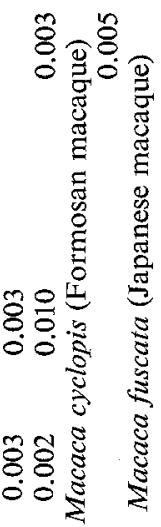

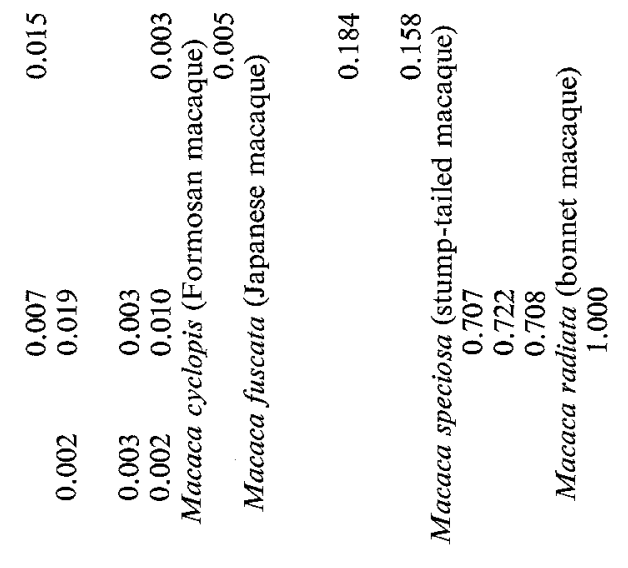

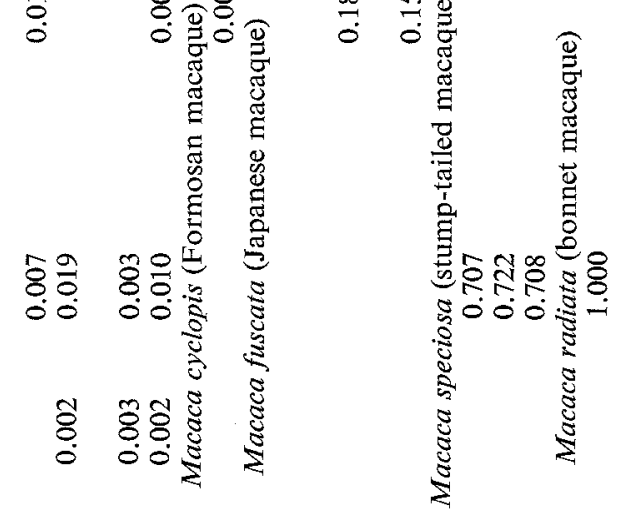

B.

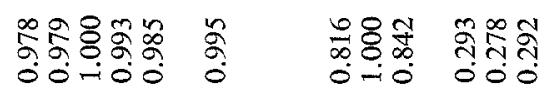

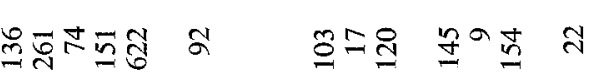
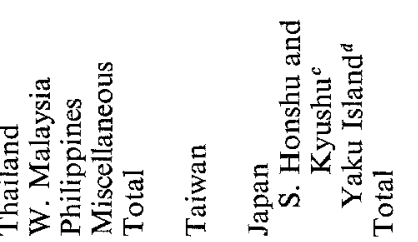

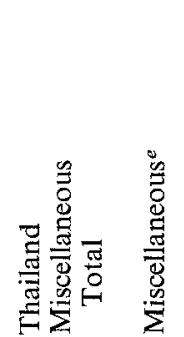


Table III. Mating Patterns for the CA I Types of Macaca nemestrina

\begin{tabular}{|c|c|c|c|c|c|c|c|c|c|}
\hline & \multicolumn{2}{|c|}{ Male parent } & & \multicolumn{3}{|c|}{ Female parent } & \multicolumn{3}{|c|}{ Offspring } \\
\hline & Phenotypes $^{a}$ & $\begin{array}{l}\text { Proposed } \\
\text { genotypes }^{b}\end{array}$ & & No. ${ }^{c}$ & Phenotypes & $\begin{array}{l}\text { Proposed } \\
\text { genotypes }\end{array}$ & No. & Phenotypes & $\begin{array}{l}\text { Proposed } \\
\text { genotypes }\end{array}$ \\
\hline I & o & $x^{-/ x^{-}}$ & $\begin{array}{l}x \\
\times \\
\times\end{array}$ & $\begin{array}{l}3 \\
1 \\
1\end{array}$ & $\begin{array}{l}o \\
b \\
b\end{array}$ & $\begin{array}{c}x^{-/ x^{-}} \\
x^{-} / b \\
b / b \\
x^{-} / b\end{array}$ & $\begin{array}{l}3 \\
1 \\
1\end{array}$ & $\begin{array}{l}o \\
o \\
b\end{array}$ & $\begin{array}{l}x^{-} / x^{-} \\
x^{-} / x^{-} \\
x^{-} / b\end{array}$ \\
\hline II & o & $x^{-} / x^{-}$ & $x$ & 1 & $\mathrm{~b}$ & $\begin{array}{r}b / b \\
x^{-/ b}\end{array}$ & 1 & $\mathrm{~b}$ & $x^{-/ b}$ \\
\hline III & a & $\begin{array}{r}a / a \\
x^{-} / a\end{array}$ & $x$ & 1 & a & $\begin{array}{r}a / a \\
x^{-} / a\end{array}$ & 1 & $\mathbf{a}$ & $\begin{array}{r}a / a \\
x^{-} / a\end{array}$ \\
\hline IV & $\mathrm{b}$ & $\begin{array}{r}x^{-} / b \\
b / b\end{array}$ & $x$ & 1 & b & $\begin{array}{r}b / b \\
x^{-} / b\end{array}$ & 1 & $\mathrm{~b}$ & $\begin{array}{r}b / b \\
x^{-} / b\end{array}$ \\
\hline & & & $x$ & 1 & o & $x^{-1 x^{-}}$ & 1 & $b$ & $x^{-/ b}$ \\
\hline & & $?$ & $\begin{array}{l}x \\
x\end{array}$ & $1^{\mathbf{a}}$ & $\begin{array}{l}a b \\
o\end{array}$ & $\begin{array}{c}a / b \\
x^{-/ x^{-}}\end{array}$ & $\begin{array}{l}1 \\
1\end{array}$ & $\begin{array}{l}a b \\
a\end{array}$ & $\begin{array}{r}a / b \\
x^{-/ a}\end{array}$ \\
\hline V & $a b$ & $a / b$ & $x$ & 1 & $\mathrm{a}$ & $x-/ a$ & 1 & $\mathrm{~b}$ & $x^{-} \mid b$ \\
\hline VI & $\mathrm{c}$ & $x^{-/ c}$ & $\begin{array}{l}x \\
x \\
x\end{array}$ & $\begin{array}{l}1 \\
1 \\
2\end{array}$ & $\begin{array}{l}o \\
o \\
b\end{array}$ & $\begin{array}{c}x^{-/} / x^{-} \\
x^{-} / x^{-} \\
b / b \\
x^{-/ b}\end{array}$ & $\begin{array}{l}1 \\
1 \\
2\end{array}$ & $\begin{array}{l}o \\
c \\
b\end{array}$ & $\begin{array}{l}x^{-/ x^{-}} \\
x^{-/ c} \\
x^{-/ b}\end{array}$ \\
\hline & & & $x$ & $1^{d}$ & $a b$ & $a / b$ & 1 & a & $x^{-/ a}$ \\
\hline
\end{tabular}

${ }^{a}$ Roman numerals indicate the six different male parents.

${ }^{b}$ Alleles designated $x$ represent suppressed CA I, electrophoretic type unknown.

$c$ Number of different females mated to same male.

d Same female.

tion, in which a " $b$ " $\times$ "o" mating produced an "a" offspring, the data indicated that the CA I types could all be under the control of alleles at the $C A I$ locus. If this is true, then type $o$ is expressed only in the recessive homozygous condition, and is not readily detectable in heterozygotes by the zymogram screening method used in this study.

The occurrence of the CA I-deficient phenotype could, in theory, be due to one of the following mechanisms: (1) an epistatic effect of a distinct, independently segregating locus, with the deficient phenotype being due to either a single or double dose of the second locus; (2) a mutation in a closely linked "control" gene for CA I acting in cis only, which has the effect of suppressing the synthesis of CA I; (3) a mutation within the structural gene for CA I which interferes in some manner with the formation of CA I. The first possibility cannot be excluded from the mating data alone (except for the abovementioned problematical " $o$ " $x$ " $b$ " mating which produced an "a" offspring), but it can be definitely excluded by an analysis of the $M$. nemestrina populations. A comparison of the observed phenotypic frequencies with those expected under an epistatic system gives chi-square values significant at the 0.001 level, thereby making the first model unlikely. The population data do not per- 
mit a distinction between the second and third models since the chi-square values are not significant in both cases. However, we feel that the previously mentioned findings of DeSimone wherein he was able to classify the deficiency hemolysates as the $a, b$, or ab phenotypes of CA I indicate that the mutation responsible for the CA I deficiency has occurred at a site which is distinct from those responsible for the electrophoretic variants of CA I. This mutated site then became associated with the other allele, or with the other closely linked $C A I$ control locus, probably by crossing over, resulting in (1) the formation of the suppressed CA I alleles $a^{-}$and $b^{-}$or (2) an association with a presumed, closely linked $C A I$ control locus $(c)$, i.e., $c^{-}, a$ and $c^{-}, b$.

\section{The CA II Variants of M. mulatta}

The genetic basis for the inheritance of the two forms of the other isozyme of carbonic anhydrase, CA II, was investigated by examining the mating patterns from a breeding colony of rhesus macaques at the University of Missouri. The mating data presented in Table IV, although based on only 11 crosses, are nevertheless compatible with the hypothesis that the CA II types a and $\mathrm{b}$ are controlled by two alleles at the $C A I I$ locus, $C A I I^{a}$ and $C A I I^{b}$. It is also reasonable to assume that the CA IIa and CA IIb types in the cynomologous macaque, $M$. irus, the stump-tailed macaque, $M$. speciosa, as well as the CA $\mathrm{IIa}_{2}$ and $\mathrm{CA} \mathrm{IIb} \mathrm{types} \mathrm{in} \mathrm{the} \mathrm{pig-tailed} \mathrm{macaque,} M$. nemestrina, are under similar genetic control (i.e., allelic).

\section{The CA I Polymorphisms}

\section{Electrophoretic Variants}

An examination of the distribution of gene frequencies in Table II shows that the macaque species can be tentatively classified into four general groups: those with a high frequency of the $C A I^{a}$ allele (M. mulatta, M. irus, M. cyclopis, and M. fuscata); those with high frequencies for both of the $C A I^{a}$ and $C A I^{b}$ alleles ( $M$. nemestrina); those with a high frequency of the $C A I^{a}$ allele ( $M$. radiata and $M$. speciosa); and those with the $C A I^{a_{2}}$ and $C A I^{d_{3}}$ alleles ( $M$. maura and $M$. niger). The high $a$ group can be further divided into those species with low frequencies of the $b, c$, and $d_{2}$ (M. mulatta, $M$. irus, and $M$. cyclopis) and $M$. fuscata in which the frequency of $d_{2}$ is moderately high. Additionally, in the high $c$ group, $M$. speciosa can be separated from $M$. radiata

Table IV. Inheritance of Carbonic Anhydrase II (CA II) Phenotypes in Macaca mulatta

\begin{tabular}{ccccc}
\hline & & \multicolumn{2}{c}{$\begin{array}{c}\text { Number and phenotypes } \\
\text { of offspring }\end{array}$} \\
\cline { 3 - 5 } Matings & $\begin{array}{c}\text { Number of } \\
\text { progeny }\end{array}$ & $\mathrm{a}$ & $\mathrm{b}$ & $\mathrm{ab}$ \\
\hline $\mathrm{a} \times \mathrm{a}$ & 4 & 4 & 0 & 0 \\
$\mathrm{ab} \times \mathrm{a}$ & 5 & 2 & 0 & 3 \\
$\mathrm{ab} \times \mathrm{ab}$ & 2 & 1 & 0 & 1 \\
\hline
\end{tabular}


in having a moderately high frequency of the $a$ allele, whereas the $c$ allele may have gone to fixation in $M$. radiata.

It would appear that the $a$ gene, because of its high interspecies frequency, either represents the ancestral gene or the one which has undergone the greatest positive selection; nevertheless, the rare alleles found in the high $a$ species (i.e., $b, c$, and $d_{2}$ ) may have been selected for in certain species, reaching high frequencies in $M$. nemestrina ( $b$ allele), $M$. speciosa and $M$. radiata ( $c$ allele), and $M . f u s c a t a\left(d_{2}\right.$ allele).

\section{The Deficiency Variant}

Several mammalian species are now known (e.g., ox, sheep, gibbon) in which the evolutionarily homologous forms of their CA I are either markedly reduced or absent (Tashian et al., 1968; Tanis et al., 1970). It thus appears that not only does CA I show greater variation than CA II, but in those species where only one form is present, its evolutionary homologies are more similar to CA II than to CA I. In other words, in certain species, CA II is seemingly able to carry out effectively all of the functions of carbonic anhydrase in the absence of CA I. In view of this, it is perhaps not too surprising that a high frequency of a deficiency in CA I can be maintained in the pigtailed macaque.

The existence of the abc polymorphism of CA I along with a polymorphic deficiency of CA I might be explained by the possibility that the deficiency phenotype is undergoing active selection at the present time, whereas the abc polymorphism is no longer being maintained by active selection. Another possibility would be that the gene (or genes) causing the deficiency phenotype and the $a, b$, and $c$ alleles are undergoing concurrent selection.

Some critical populations to examine with respect to selection or to the priorities of these two polymorphisms would seem to be those from the islands of Borneo and Sumatra. For example, if the deficiency phenotype of CA I is not present in the island populations, and the frequencies of the $a, b$, and $c$ genes are similar to those of the mainland population, it would suggest that the polymorphic deficiency of CA I has evolved more recently than the electrophoretic polymorphism. Furthermore, if the frequencies of these polymorphic genes are similar for both the mainland and island populations, it would suggest that active selection is responsible for the maintenance of these polymorphisms.

A situation somewhat similar to the polymorphic deficiency of $\mathrm{CA} I$ has been reported for one of the two lactate dehydrogenase loci, $L D H B$, in mouse erythrocytes (Shows and Ruddle, 1968). Because this polymorphism is limited to the red cells, the authors believe that a mutation in a postulated regulator locus for $\mathrm{LDH} \mathrm{B}$, and not one in the structural gene for LDH B, is the best interpretation of their findings.

\section{The Carbonic Anhydrase II Polymorphisms}

Although fewer individuals were typed for CA II than for CA I, the macaque species could be classified into three groups on the basis of the allelic frequencies of CA II: those species with a high frequency of $C A I I^{a}$ (M. speciosa and $M$. fuscata); those with a high frequency of $C A I I^{b}(M$. nemestrina, $M$. maura, and $M$. niger); and those with 
approximately equal frequencies of $C A I^{a}$ and $C A I^{b}$ (M. mulatta and $M$. irus). In the high $b$ group, the Celebes macaques, $M$. maura and $M$. niger, can be separated from the pig-tailed macaques, in that the $a_{2}$ allele is present in moderately high frequency in the latter species, whereas the $b$ gene may be monomorphic in the macaques from Celebes.

An intriguing comparative feature of the variations at the $C A I I$ locus is the extensive polymorphism of the $a$ and $b$ alleles in the rhesus and cynomolgous macaques. This situation is even more striking when one considers that not only is $C A I I$ apparently more evolutionarily conservative than $C A I$ (Tashian et al., 1968), but $C A I$ is essentially monomorphic in both species. The findings of the same polymorphism in these species gives further support to the probability that $M$. mulatta and $M$. irus are indeed conspecific, a hypothesis which has been previously based on the observations that the two species interbreed in their regions of overlap in Thailand (Fooden, 1964).

\section{Comparative Evolution of the Carbonic Anhydrase Isozymes}

Unfortunately, more complexity than insight concerning the possible selective mechanisms which can affect the isozymes of carbonic anhydrase has emerged from the present study. Even though polymorphisms seem to be maintained in three species of macaques for both CA I ( $M$. nemestrina, $M$. speciosa, and $M$. fuscata) and CA II ( $M$. mulatta, $M$. irus, and $M$. nemestrina), nevertheless, only three presumed allelic forms of CA II were observed compared to the seven (or possibly nine) alleles for CA I. Also since $M$. mulatta and $M$. irus are probably conspecific, only two species, instead of three, are polymorphic at the $C A I I$ locus. Thus, these data tend to support the hypothesis that CA I has been "permitted" (evolutionarily) to incorporate greater molecular variation than has CA II (Tashian et al., 1968). It should be pointed out, however, that polymorphisms have been reported for the red cell carbonic anhydrases of the sheep and ox (Sartore et al., 1969: Tucker et al., 1967), species whose erythrocytes contain only one major form of carbonic anhydrase which seems to be homologous to CA II (cf. Tanis et al., 1970). A polymorphism of red cell carbonic anhydrase has also been reported for the horse (Sandberg, 1968); however, since the horse is known to have both CA I and CA II (Furth, 1968), it is not clear which of the carbonic anhydrases (or both) are polymorphic. Of the primate species other than macaques studies to date, polymorphisms for electrophoretic variants of CA I have been reported for the baboon (Barnicot et al., 1964; Tashian et al., 1968) and the orangutan (Tashian et al., 1968).

A somewhat similar situation to that of the carbonic anhydrases, wherein one of two genes controlling an isozyme system appears to undergo greater variability than the other, may be that which is found in the lactate dehydrogenase (LDH) isozymes. The molecular interaction between the two enzymes is, however, somewhat different in that the two isozymes of carbonic anhydrase do not polymerize, whereas the two genetic subunits of $\mathrm{LDH}$ ( $\mathrm{LDH} \mathrm{B}$ and $\mathrm{LDH} \mathrm{A}$ ) polymerize as tetramers to produce five isozymic molecules. Nevertheless, not only is more genetic variability observed in $\mathrm{LDH} \mathrm{B}$ than in $\mathrm{LDH} \mathrm{A}$ for the different populations of the frogs Rana pipiens and Rana palustris over their extensive ranges in North and Central America (Salthe, 1969), but genetic and phylogenetic variation has been reported in rodents in which the 
suppression of red cell LDH B is postulated to be under the control of a regulator locus for LDH B (Shows and Ruddle, 1968; Shows et al., 1969).

One explanation for the differential evolution of CA I and CA II might be that perhaps one isozyme is selectively more neutral than the other isozyme. This concept can be applied to the two carbonic anhydrases in the sense that CA I appears to be less essential than CA II for its $\mathrm{CO}_{2}$ hydrase function. This assumption is based on the fact that although six to seven times as much CA I as CA II is present in macaque hemolysates, the turnover for the $\mathrm{CO}_{2}$ hydration reaction of CA II in vivo may be as much as 40 times that of CA I (Gibbons and Edsall, 1964; Duff and Coleman, 1966). Thus, the contribution of $\mathrm{CA} \mathrm{I}$ to the total $\mathrm{CO}_{2}$ hydrase activity of erythrocytes may be less than $13-15 \%$; it should be pointed out, however, that by analogy with the human carbonic anhydrases (Gibbons and Edsall, 1964), the macaque CA I probably has a lower $K_{m}$ than CA II, which indicates that CA I may be more effective than CA II in its $\mathrm{CO}_{2}$ hydrase activity at low substrate concentrations.

The concept that reduction in selective constraints permits greater variability can possibly also be seen when the $\beta$-chain of $\mathrm{Hb} \mathrm{A}$ is compared with the $\delta$-chain of $\mathrm{Hb} \mathrm{A}_{2}$ (Boyer et al., 1969). These authors suggest that one of the reasons which might account for the greater polymorphic and evolutionary variation in $\mathrm{Hb}_{2}$ compared to $\mathrm{Hb} \mathrm{A}$ in New World monkeys could be that the greatly reduced levels of $\mathrm{Hb} \mathrm{A}_{2}$ have made the $\delta$-chain less susceptible to the selective constraints exerted on the $\beta$-chain, thereby enabling it to undergo adaptive Darwinian evolution. It will be most interesting to see whether this concept of relaxed constraints leading to greater variability will be borne out when additional comparisons are made between selectively constrained and "liberated" protein molecules.

Another interpretation of these differences between the carbonic anhydrases could be that although selection which is related to $\mathrm{CO}_{2}$ hydrase activity does occur, as evidenced by the CA II polymorphisms, selection relating to some aspect of the high specific esterase activity of CA I in macaques (Tashian et al., 1968) might be responsible for maintaining some of the CA I polymorphisms. The high esterase activity of CA $\mathrm{I}$ in orangutan and baboon, two species which show rather extensive polymorphisms at the $C A I$ locus (Tashian et al., 1968) would seem to support this concept. Such primate species as man, gorilla, and chimpanzee whose CA I and CA II esterase activities (within the same animal) are similar (Tashian, unpublished) appear to show only rare variants of CA I. It will be interesting to see whether further testing of different mammalian carbonic anhydrases will support this hypothesis.

\section{CONCLUSIONS}

Three possibilities could account for the fact that greater evolutionary change has taken place in one isozyme of carbonic anhydrase than in the other. First, selective constraints could be acting on the CA II molecules in order to preserve certain structural features essential for the maintenance of their functionally vital, high $\mathrm{CO}_{2}$ hydrase activity. Second, because this hydrase activity is greatly reduced in the CA I molecules, active selection would be occurring for some feature other than the hydrase activity of the CA I molecules which are free of the constraints exerted on CA II. 
Third, the reduced constraints on CA I might be allowing neutral mutations to proceed more readily to fixation in this molecule by such mechanisms as random genetic drift.

While the lack of sequence data for the various electrophoretic variants existing in the different macaque populations precludes an estimation of the evolutionary rates of the CA I and CA II molecules in terms of amino acid substitutions per generation, it can be noted that the apparent rate of incorporation of mutations differs for the two molecules. Under the reasonable assumption that the rate of mutation is the same for both CA I and CA II, and with the assumption that the number of variant forms incorporated into the population genome was the same for both CA I and CA II at the time of divergence of the macaques from related groups, then it seems likely that different selective pressures have been operating on these molecules during the evolution of the different macaque species. Furthermore, given the low probability of fixation of neutral alleles (Kimura and Ohta, 1969a,b), the establishment of high frequencies of the presumably new variant alleles in different species of macaques indicates that the variability of the CA I molecule in this genus is more probably due to disruptive selection rather than to random, non-Darwinian variability (cf. King and Jukes, 1969).

\section{ACKNOWLEDGMENTS}

We wish to thank Dr. William Prychodko, as well as all those individuals mentioned in the Materials and Methods section who gave so generously of their time to help us obtain the macaque bloods that were used in this study. We are particularly grateful to Dr. James A. Gavan and Dr. Lloyd A. Dillingham for providing the blood specimens that were used for the analysis of the mating data. Our interpretation of the electrophoretic results was greatly facilitated by the meticulous and expert assistance of the late Arthur A. Smiltens. We also wish to acknowledge the excellent technical help of Mrs. Emily Poulik, Dr. Mark Weiss, and Mr. Ronald Griffith. Discussions with Dr. James V. Neel, Dr. Charles F. Sing, and Dr. Donald C. Shreffler concerning various aspects of this study have been especially helpful.

\section{REFERENCES}

Barnicot, N. A., Jolly, C., Huehns, E. R., and Moor-Jankowski, J. (1964). A carbonic anhydrase variant in the baboon. Nature 202: 198.

Bernstein, I. S. (1966). Naturally occurring primate hybrid. Science 154: 1559.

Boyer, S. H., Crosby, E. F., Thurmon, T. F., Noyes, A. N., Fuller, G. F., Leslie, S. E., Shepard, M. K., and Herndon, C. N. (1969). Hemoglobins $A$ and $A_{2}$ in New World primates: Comparative variation and its evolutionary implications. Science 166: 1428.

Derrien, Y., and Laurent, G. (1969). The erythrocyte carbonic anhydrases. Exposés Annuels Biochim. Méd., Ser. 29, p. 167.

Duff, T. A., and Coleman, J. E. (1966). Macaca mulatta carbonic anhydrase. Crystallization and physiochemical and enzymatic properties of two isozymes. Biochemistry 5: 2009.

Edsall, J. (1968). The carbonic anhydrases of erythrocytes. Harvey Lectures, Ser. 62, p. 191.

Epstein, C. J., and Schechter, A. N. (1968). An approach to the problem of conformational isozymes. Ann. N.Y. Acad. Sci. 151: 85.

Fooden, J. (1964). Rhesus and crab-eating macaques: Integradation in Thailand. Science 143: 363. 
Fooden, J. (1969). Taxonomy and evolution of the monkeys of Celebes (primates: Cercopithecidae). Bibliotheca Primatologica, No. 10, S. Karger, Basel, New York, pp. 1-148.

Funakoshi, S., and Deutsch, H. F. (1968). Human carbonic anhydrases. I. Isolation and demonstration of isozymes in erythrocytes. J. Biol. Chem. $243: 6474$.

Funakoshi, S., and Deutsch, H. F. (1969). Human carbonic anhydrases. II. Some physiochemical properties of native isozymes and of similar isozymes generated in vitro. J. Biol. Chem. 244: 3488 .

Furth, A. J. (1968). Purification and properties of horse erythrocyte carbonic anhydrases. J. Biol. Chem. 243: 4832 .

Gibbons, B. H., and Edsall, J. T. (1964). Kinetic studies of human carbonic anhydrases B and C. J. Biol. Chem. $239: 2539$.

Headings, V. E., and Tashian, R. E. (1970a). A radioimmunoassay for quantifying carbonic anhydrase isozymes in crude lysates. Biochem. Genet. 4: 285.

Headings, V. E., and Tashian R. E. (1970b). Quantitative genetic variation in carbonic anhydrase isozymes from blood cells and other tissues of the pig-tailed macaque, Macaca nemestrina (submitted for publication).

Kimura, M., and Ohta, T. (1969a). The average number of generations until fixation of a mutant gene in a finite population. Genetics 61: 763 .

Kimura, M., and Ohta, T. (1969b). The average number of generations until extinction of an individual mutant gene in a finite population. Genetics 63: 701 .

King, J. L., and Jukes, T. H. (1969). Non-Darwinian evolution. Science 164: 788.

Nesturkh, M. (1959). The Origin of Man, Foreign Languages Publishing House, Moscow.

Nyman, P. O., Strid, L., and Westermark, G. (1968). Carboxy-terminal region of human and bovine erythrocyte carbonic anhydrases. I. Amino acid sequences of terminal cyanogen bromide fragments. European J. Biochem. 6: 172.

Reed, T. E., and Schull, W. J. (1968). A general maximum likelihood estimation program. Am. J. Human Genet , 20: 579.

Salthe, S. N. (1969). Geographic variation of the lactate dehydrogenases of Rana pipiens and Rana palustris. Biochem. Genet. 2: 271.

Sandberg, K. (1968). Genetic polymorphism in carbonic anhydrase from horse erythrocytes. Hereditas 60: 411 .

Sartore, G., Stormont, C., and Grunder, A. A. (1969). Multiple electrophoretic forms of carbonic anhydrase in red cells of domestic cattle (Bos taurus) and American buffalo (Bison bison). Genetics 61: 823 .

Shows, T. B., and Ruddle, F. H. (1968). Function of the lactate dehydrogenase $B$ gene in mouse erythrocytes: Evidence for control by a regulator gene. Proc. Natl. Acad. Sci. 61: 574.

Shows, T. B., Massaro, E. J., and Ruddle, F. H. (1969). Evolutionary evidence for a regulator gene controlling the lactate dehydrogenase $B$ gene in rodent erythroctyes. Biochem. Genet. 3: 525 .

Tanis, R. J., Tashian, R. E., and Yu, Y.-S. L. (1970). Properties of carbonic anhydrase isozymes isolated from porcine erythrocytes. J. Biol. Chem. 245: 6003.

Tashian, R. E. (1965). Genetic variation and evolution of the carboxylic esterases and carbonic anhydrases of primate erythrocytes. Am.J. Human Genet. 17: 257.

Tashian, R. E. (1969). The esterases and carbonic anhydrases of human erythrocytes. In Yunis, J. J. (ed.), Biochemical Methods in Red Cell Genetics, Academic Press, New York, pp. 307-336.

Tashian, R. E., Shreffler, D. C., and Shows, T. B. (1968). Genetic and phylogenetic variation in the different molecular forms of mammalian erythrocyte carbonic anhydrases. Ann. N.Y. Acad. Sci. 151: 64 .

Tucker, E. M., Suzuki, Y., and Stormont, C. (1967). Three new phenotypic systems in the blood of sheep. Vox Sanguinis 13: 246. 